\title{
Inhomogeneous distributions of Meiyu rainfall in the Jiang-Huai basin, and associated circulation patterns
}

\author{
Lijuan Wang ${ }^{1,2, *}$, Qinglan Huang ${ }^{1,3}$, Aiguo Dai ${ }^{2}$, Zhaoyong Guan ${ }^{1}$, Jinhai He ${ }^{1}$, \\ Zhiwei $\mathrm{Wu}^{1}$
}

\author{
${ }^{1}$ Key Laboratory of Meteorological Disaster of Ministry of Education, College of Atmospheric Sciences, \\ Nanjing University of Information Science \& Technology, Nanjing 210044, PR China \\ ${ }^{2}$ National Center for Atmospheric Research, Boulder, Colorado 80307, USA \\ ${ }^{3}$ Jiangmen Meteorological Bureau, Jiangmen 529030, Guangdong, PR China
}

\begin{abstract}
Using station rainfall data and NCEP/NCAR reanalysis from 1978-2007, we characterize the spatial variations of the heavy rainfall (Meiyu) during June-July over the Jiang-Huai basin ( $\mathrm{JHB}, \sim 28^{\circ}-34^{\circ} \mathrm{N}$ and $110^{\circ}-122^{\circ} \mathrm{E}$ ) in East China and their associated atmospheric circulations. An empirical orthogonal function (EOF) analysis of the Meiyu rainfall revealed 2 other significant modes besides the dominant basin-wide in-phase mode. They include a north-south dipole (out-of-phase) pattern (EOF 2) and a roughly east-west dipole pattern (EOF 3). During the 'south flood and north drought' (SF/ND) phase of EOF 2, the western Pacific subtropical high (WPSH) is displaced southward, which prevents the East Asian summer monsoon from reaching as far north as in normal years. A cyclonic anomaly circulation at $850 \mathrm{hPa}$ occurs over Southeast China and an ascending (descending) anomaly motion south (north) of $\sim 30^{\circ} \mathrm{N}$ is seen over the $\mathrm{JHB}$, which contributes to the excess (lack) of Meiyu rainfall south (north) of $\sim 30^{\circ} \mathrm{N}$ over the JHB during the SF/ND years. During the opposite phase of this mode, these anomaly circulation patterns are roughly reversed. During the 'east wet and west dry' phase of EOF 3, the WPSH is displaced eastward, and a cyclonic anomaly circulation centered south of Japan brings more moisture from the Yellow and East China Seas into the eastern part of the JHB; while southwesterly vapor fluxes past over the western part of the JHB and converges over North China, leaving the western part of the JHB relatively dry. During the opposite phase, the WPSH is shifted northwestward, and the anomaly moisture transports are reversed over the JHB.
\end{abstract}

KEY WORDS: Meiyu rainfall · East Asian summer monsoon · Western Pacific sub-tropical high · Atmospheric circulation

Resale or republication not permitted without written consent of the publisher

\section{INTRODUCTION}

Each year, as the summer monsoon develops and advances northward over East Asia, a seasonal rain band moves from the sub-tropics to higher latitudes during the late spring and early summer. After lasting for about one month and with the southward withdrawal of the monsoon winds, the rainy season often abruptly comes to an end in East Asia (Tao \&
Chen 1987, Ding 1992, Lau \& Yang 1997). The seasonal torrential rain band usually lasts from mid-June to mid-July over the Jiang-Huai basin $\left(\mathrm{JHB}, \sim 28^{\circ}-\right.$ $34^{\circ} \mathrm{N}$ and $110^{\circ}-122^{\circ} \mathrm{E}$ ) in East China, where the monsoon rainfall is called Meiyu. The same rain band extends to southern Japan (called Baiu) and advances to the Korean Peninsula (called Changma), thereby forming the typical rainy season over East Asia (Ding \& Chan 2005). Meiyu rainfall is an important compo- 
nent of the East Asian summer monsoon. Variations in Meiyu rainfall often lead to summer floods and drought over East China, causing large losses to human lives and to the Chinese economy. As a result, Meiyu rainfall has been the subject of research for many atmospheric scientists, especially in Asia (e.g. Ninomiya \& Murakami 1987, Chen 2004, Ding et al. 2007, Lu et al. 2010).

Previous studies have quantified the various characteristics of the large-scale atmospheric circulation associated with the Meiyu, including its spatial structures and multi-scale interactions within the Meiyu system (Ninomiya 2000, Yoshiaki \& Kozo 2005, Ding et al. 2007, Zheng et al. 2008) and the relationship between the Indian summer monsoon and Meiyu rainfall (Kripalani \& Kulkarni 2001). For example, studies have shown that changes in the position of the summer westerly jet-stream in the upper troposphere over East Asia have a major impact on the summer rainfall over the JHB region (Kuang \& Zhang 2006, Du et al. 2008). The teleconnection pattern from the west coast of India via Bay of Bengal to JHB and south of Japan induces the Meiyu's establishment (Liu \& Ding 2008). The Indian summer monsoon's vapor transportation can affect summer rainfall over JHB by influencing the intensity of the western Pacific subtropical high (WPSH) (e.g. Zhang 2001). The antecedent land cover (vegetation, soil moisture, snow cover, etc.) also plays an important role in modulation of the subsequent circulation for East Asian summer monsoon rainfall by changing the heat, water vapor and radiation flux from the land surface to the atmosphere (Lee et al. 2008, 2009). Many studies have investigated the occurrence, development and variation of the JHB Meiyu rainfall as a single system (e.g. Xu et al. 2001, Mao et al. 2009) and the complex circulation patterns associated with strong and weak Meiyu periods (e.g. Hu et al. 2008, Mao et al. 2008). A major feature (Hu et al. 2008 ) is that during years with above normal Meiyu rainfall over the whole JHB region, there exists a persistent high pressure center in the mid-troposphere from Yakutsk to the Sea of Okhotsk that blocks the northward movement of the WPSH. That causes a southward shift of both the cold air mass and westerlies over East China during the Meiyu period, and helps the formation of a stationary cold front along the middle-lower reaches of the Yangtze river; whereas during the weak Meiyu years, such a blocking high pressure center is not obvious or is situated further to the northeast (Hu et al. 2008).

Further analyses examined spatial variations of Meiyu rainfall within the JHB region, as these varia- tions often cause regional drought and floods within the JHB region (Lu \& Xu 1990, Qian et al. 2007). For example, in their empirical orthogonal function (EOF) analysis of pentad rainfall data for June-July from 61 stations within the JHB region, Wang \& Qian (2004) divided the JHB into 4 subdivisions: a northern and a southern part, and a middle and a lower section of the Yangtze River basin, and showed that the Meiyu rainfall differs in seasonal timing among the subdivisions. Using a rotated EOF analysis of the June-July rainfall from 63 stations, Min \& Qian (2009) also examined the sub-divisional features in Meiyu rainfall over the JHB region. Zhu et al. (2007) noted that the JHB precipitation has diverse spatial patterns, particularly the one with rainfall anomalies in the north opposite to the south. Recently, Qian et al. (2009) showed that since the end of the 20th century, the long-term trend and interannual variability of rainfall between the Jiangnan region $\left(\sim 26^{\circ}-32^{\circ} \mathrm{N}\right.$ and $\left.110^{\circ}-120^{\circ} \mathrm{E}\right)$ and Huaihe River Basin $\left(\sim 32^{\circ}-35^{\circ} \mathrm{N}\right.$ and $110^{\circ}-120^{\circ} \mathrm{E}$ ) has shown opposite features, with the Meiyu rainfall in the Huaihe River Basin (Jiangnan region) on the increase (decrease). As shown by $\mathrm{Si}$ et al. (2009), the Meiyu rainfall in the JHB region is marked by a northward shift during recent decades.

These studies demonstrate that Meiyu precipitation within the JHB region contains considerable spatial variations. The goal of this study was to further quantify the spatial patterns of the Meiyu rainfall within the JHB region, and investigate the associated atmospheric circulations. We performed an EOF analysis of 1978-2007 Meiyu precipitation to identify the leading modes of variability within the JHB region and used multi-year composites to quantify the atmospheric circulation patterns associated with the EOF modes of Meiyu rainfall. Our results should help forecast floods and droughts within the JHB region.

\section{DATA AND METHODS}

We used the quality-controlled daily precipitation data from 1978-2007 from 752 stations over China compiled by the China Meteorological Administration (CMA, http://cdc.cma.gov.cn/shuju/index.jsp? current=2\&tpcat=SURF). We selected 596 stations with few missing observations for this study. We defined the Meiyu rainfall region based on the rainfall correlation patterns, following the approach of Ting \& Wang (1997). We first computed the accumulative rainfall amount (referred to as the Meiyu rainfall) during the typical most active Meiyu period from June 16 to July 15, and then computed the SD of the 
Meiyu rainfall at each station. The Huangshan station $\left(30.13^{\circ} \mathrm{N}, 118.15^{\circ} \mathrm{E}\right)$ has the largest SD within the JHB region. We correlated the annual time series of the cumulative Meiyu rainfall from the Huangshan station with those from other stations (Fig. 1). There are 42 stations located within the shaded areas in Fig. 1 that approximately correspond to the traditional definition of the JHB Meiyu region.

With the Meiyu region defined, we then defined the start and end dates of the Meiyu period over the whole region for each year during 1978-2007, as these dates varied from year to year. These criteria were derived based on previous studies and are discussed in more detail in Huang et al. (in press). A 'rainy day' was defined based on 2 aspects: (1) there were more than 10 rainy stations in the Meiyu region, and (2) the daily precipitation amount was more than $125 \mathrm{~mm}$ in the Meiyu region (this amount was about one half of average daily rainfall in June and July). The Meiyu rainfall started on the first rainy day when the following 2 criteria were met and lasted for more than 3 d during May-June, with the South China Sea summer monsoon establishment day as the earliest possible onset day of the JHB Meiyu: (1) the $120^{\circ} \mathrm{E}$ ridge line of the WPSH was at or north of $20^{\circ} \mathrm{N}$ on the $500 \mathrm{hPa}$ level, and (2) the $120^{\circ} \mathrm{E}$ pseudo-equivalent potential temperature $\theta_{\mathrm{se}}=336 \mathrm{~K}$ isotherm was at or north of $29^{\circ} \mathrm{N}$ on the $850 \mathrm{hPa}$ level. The Meiyu period

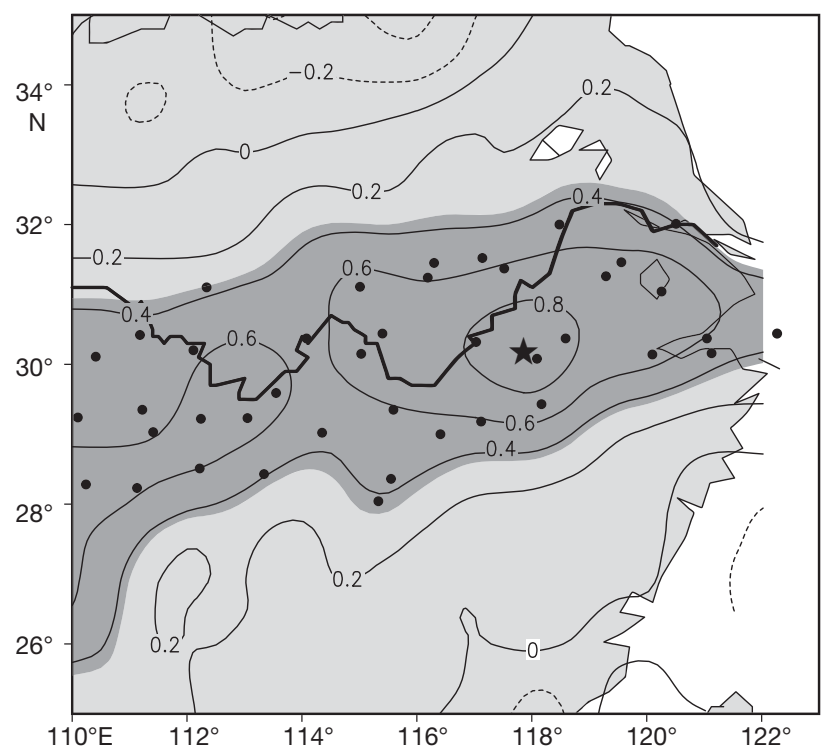

Fig. 1. Distribution of the correlation coefficient of Meiyu rainfall between the Huangshan station $(\star)$ and other stations. The correlation coefficient is significant at the $5 \%$ level within the shaded area, which approximately corresponds to the Jiang-Huai basin (JHB). The black dots represent the 42 stations within the JHB region. Dashed contour lines are used for negative values ended on the first no-rain day when the following 2 indices occurred at the same time and lasted for 3 successive days after the Meiyu started: (1) either the $120^{\circ} \mathrm{E}$ WPSH ridge line was at or north of $26^{\circ} \mathrm{N}$ on the $500 \mathrm{hPa}$ level, or the $115^{\circ}-125^{\circ} \mathrm{E}$ averaged $5880 \mathrm{gpm}$ isoline was at or north of $31^{\circ} \mathrm{N}$, and (2) on the $850 \mathrm{hPa}$ level, $120^{\circ} \mathrm{E} \theta_{\mathrm{se}}=336 \mathrm{~K}$ isotherm was at or north of $35^{\circ} \mathrm{N}$.

Using these definitions, we obtained the Meiyu period and computed the accumulative Meiyu rainfall amount for each year during 1978-2007 for each of the 42 stations within the JHB region. An EOF analysis of the accumulative Meiyu rainfall at the 42 stations was performed and the EOF coefficients were mapped out using linear interpolation. Previous studies (Hu et al. 2008, Mao et al. 2008) suggest that, given the station distribution in the JHB, analyses of station data directly or gridding the station data first produced similar results.

To derive the composite atmospheric circulation patterns associated with the leading EOF modes, NCEP/NCAR reanalysis daily data (on a $2.5^{\circ}$ grid, Kalnay et al. 1996) from 1978-2007 for geopotential height, winds, vertical velocity, air temperature, and relative humidity were also used. The reason for choosing the post-1977 data was availability of higher quality and more reliable data, particularly in NCEP/NCAR data (e.g. Ashok et al. 2007).

\section{SPATIOTEMPORAL PATTERNS OF THE JHB MEIYU RAINFALL}

The 3 leading EOFs (Fig. 2) of the JHB Meiyu rainfall account for $68.04 \%, 11.24 \%$ and $4.29 \%$ of the total variance. These are statistically robust modes based on the test of North et al. (1982). Together, they account for most $(83.57 \%)$ of the variance of the JHB Meiyu rainfall during 1978-2007.

The first EOF (Fig. 2a) is characterized by in-phase changes across the whole JHB region, but accompanied by 2 local centers, with the maximal core around $30.2^{\circ} \mathrm{N}$ and $118.0^{\circ} \mathrm{E}$ near Huangshan Mountain and a secondary maximum around $28.0^{\circ} \mathrm{N}$ and $113.5^{\circ} \mathrm{E}$. The related temporal coefficient curve (Fig. 2b) depicts mostly variations on 4 to 5 yr time scales, with a slight downward trend. Since this mode accounts for $68 \%$ of the total Meiyu variance, Fig. 2a,b suggests that the dominant variations are quasi 4 to $5 \mathrm{yr}$ oscillations for the JHB Meiyu rainfall. In other words, it is likely to have a few dry summers after a couple of wet Meiyu seasons. This information can be very useful to local governments and farmers for forecasts of 

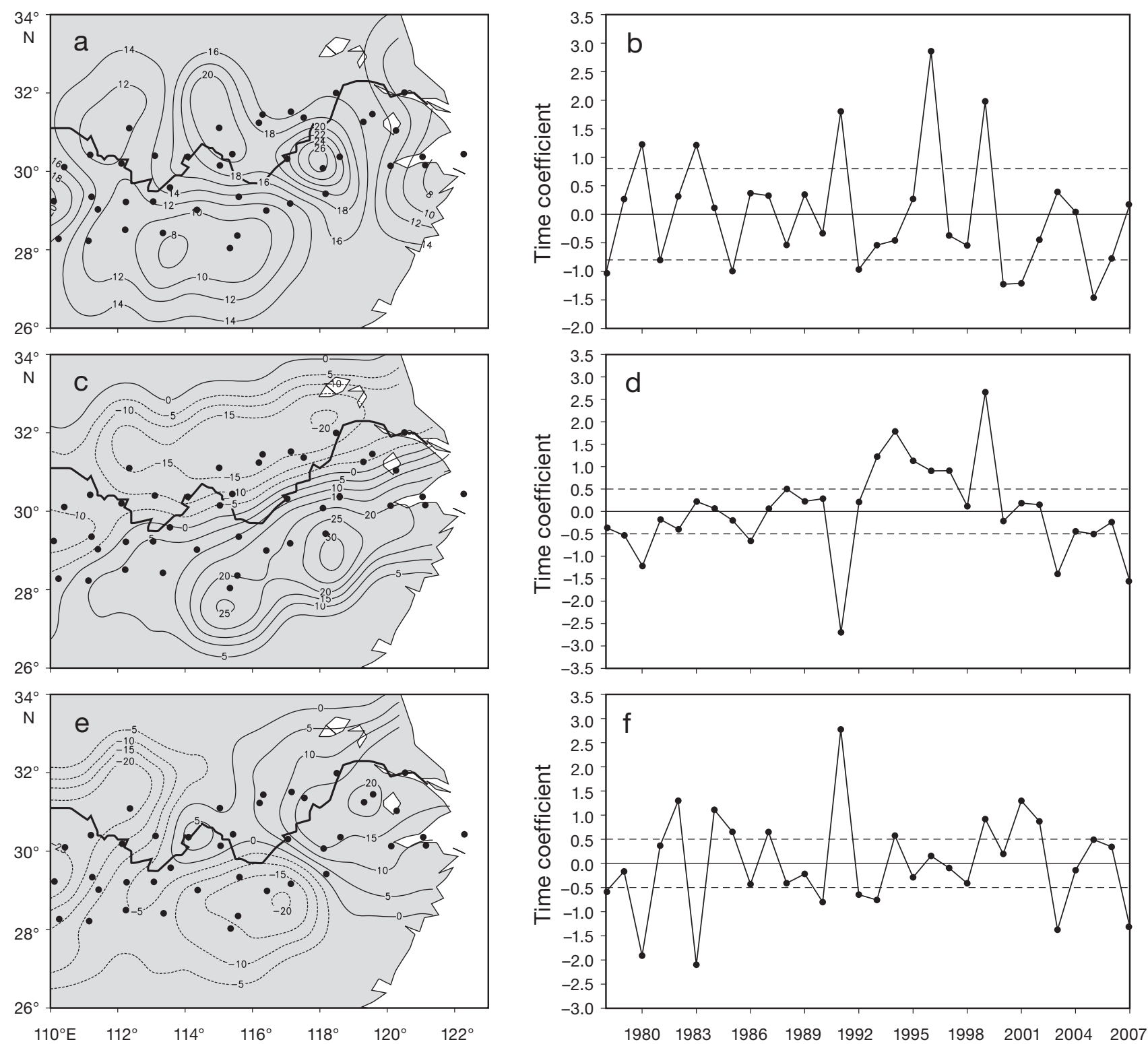

Fig. 2. Spatial patterns of the 3 leading EOF modes of Meiyu rainfall: (a) EOF 1, (c) EOF 2, (e) EOF 3, and the locations of the 42 stations within the Jiang-Huai basin (filled circles). The corresponding (b, d, f) normalized temporal coefficients are shown with the \pm 0.8 SD range for EOF 1 and \pm 0.5 SD range for EOFs 2 and 3 (dashed line). In (a), (c) and (e), dashed contour lines are used for negative values

droughts and floods and mitigating their impacts. Our EOF 1 patterns are consistent with previous analyses (e.g. Mao et al. 2008).

The second EOF (Fig. 2c) shows an out-of-phase rainfall pattern between the areas north and south of about $30^{\circ} \mathrm{N}$. Here we refer to this mode as the 'southern flood and northern drought' (SF/ND) or 'southern drought and northern flood' (SD/NF) pattern (Zhu et al. 2007, Niu et al. 2011), which shows the local discrepancy of precipitation in the 2 zones of the JHB. As shown by the associated temporal coefficients
(Fig. 2d), this mode has relatively small interannual variations, and exhibits mostly decadal changes, with small amplitudes in the 1980s, relatively large variations (mostly positive, i.e. SF/ND pattern) in the 1990s, and negative coefficients (i.e. SD/NF pattern) in the first decade of this century. In particular, 1991 and 1999 have the largest amplitudes for this mode during 1978-2007. Unfortunately, the dominant EOF 1 also has large amplitudes in these 2 years, which makes it difficult to separate the atmospheric circulation patterns associated with the 2 EOFs using the 
reanalysis data for these years in the composite analysis (see Section 4.1).

The third EOF (Fig. 2e) accounts for a relatively small variance $(4.29 \%)$. Nevertheless, it represents a pattern of rainfall anomalies out-of-phase roughly in the east-west direction, with wet (dry) conditions in the eastern part of the middle and lower Yangtze basin (MLYB) accompanied by dry (wet) conditions in the western part of the MLYB (referred to as EW/WD [ED/WW] patterns). The associated temporal coefficients (Fig. 2f) show that this mode varies mostly on interannual time scales, with small interdecadal variations.

The above results show that, to the first order, the JHB Meiyu rainfall indeed varies in phase across the region, and thus can be investigated as a whole. Nevertheless, the spatial heterogeneity represented by EOFs 2 and 3 is non-negligible. For some years, although rainfall is normal for the JHB region as a whole, localized floods and drought may still occur, causing severe disasters in parts of the JHB region.

\section{ATMOSPHERIC ANOMALY CIRCULATIONS ASSOCIATED WITH MEIYU RAINFALL PATTERNS}

To select the years for composite analysis of atmospheric circulation patterns, we first normalized the temporal coefficients of the leading 3 EOFs using their SD. In view of the rapid decreasing contributions to the total variance by the leading EOFs, years included in the composites of preceding EOFs were excluded in the composites of the remaining EOFs. To obtain reasonable sample sizes, we selected years with a normalized coefficient outside the $\pm 0.8( \pm 0.5)$ $\mathrm{SD}$ range for inclusion in the composite analysis for EOF 1 (EOF 2 and 3). There are 6 composites, with 2 phases for each EOF mode (Table 1). Due to the limited record length, the ED/WW pattern for EOF 3 contains only one year, and thus the corresponding circulation patterns may not be very representative. We realize that there are other ways to analyze the circulation patterns associated with the leading EOF modes, such as correlating the temporal coefficients with a circulation field. We chose the composite method for its simplicity. Note that only the days within the Meiyu period for the selected years were used for the composites below.

The years for the 2 phases of EOF 1 listed in Table 1 are the same as those for wet and dry years for the JHB Meiyu rainfall as a whole. This is expected as EOF 1 accounts for $68 \%$ of the total variance. Many studies (e.g. Hu et al. 2008, Mao et al. 2008) have
Table 1. Years selected for circulation composites for different Meiyu rainfall patterns. JHB $=$ Jiang-Huai basin; $\mathrm{SF} / \mathrm{ND}=$ south flood and north drought; SD/NF = south drought and north flood; EW/WD = east wet and west dry; ED/WW = east dry and west wet

\begin{tabular}{|ll|}
\hline Meiyu pattern & Years \\
\hline EOF 1 & \\
Whole JHB flood & $1980,1983,1991,1996,1999$ \\
Whole JHB drought & $1978,1981,1985,1992,2000$, \\
& 2001,2005 \\
EOF 2 & $1988,1993,1994,1995,1997$ \\
SF/ND & $1979,1986,2003,2007$ \\
SD/NF & \\
EOF 3 & $1982,1984,1987,2002$ \\
EW/WD & 1990 \\
ED/WW & \\
\hline
\end{tabular}

examined the composite circulation patterns for those years, as described in the Introduction. Here we focus on atmospheric anomaly circulations associated with EOFs 2 and 3, especially the SF/ND and $\mathrm{SD} / \mathrm{NF}$ patterns for EOF 2, since these patterns have not been well examined. Furthermore, the SF/ND and EW/WD patterns are often associated with severe floods (e.g. 2003 and 2007) and severe drought (e.g. 1988) over the Huaihe valley. Thus, studying these patterns is of practical importance.

The composite anomalies of Meiyu rainfall for the years with the SF/ND and SD/NF show an out-ofphase rainfall pattern between the areas north and south of about $29^{\circ}-30^{\circ} \mathrm{N}$, which shows the local discrepancy of precipitation between the north and south of the JHB (Fig. 3a,b). A pattern of Meiyu rainfall anomalies out-of-phase roughly in the east-west direction can be seen in Fig. 3c,d.

\subsection{Anomaly circulations associated with the SF/ND and SD/NF Meiyu patterns}

There are 5 and $4 \mathrm{yr}$ included in the SF/ND and $\mathrm{SD} / \mathrm{NF}$ composite analyses, respectively (Table 1). The composite maps of $500 \mathrm{hPa}$ geopotential height anomalies (relative to the 1978-2007 mean) show that in the SF/ND years (Fig. 4a), the anomalies are mostly negative over East Asia and the western Pacific north of about $25^{\circ} \mathrm{N}$, which suggests that the WPSH is positioned southward of its mean location (south of about $25^{\circ} \mathrm{N}$ ). A band of negative anomalies runs from the Sea of Okhotsk to East China, and the coastal trough is stronger than normal, which does 

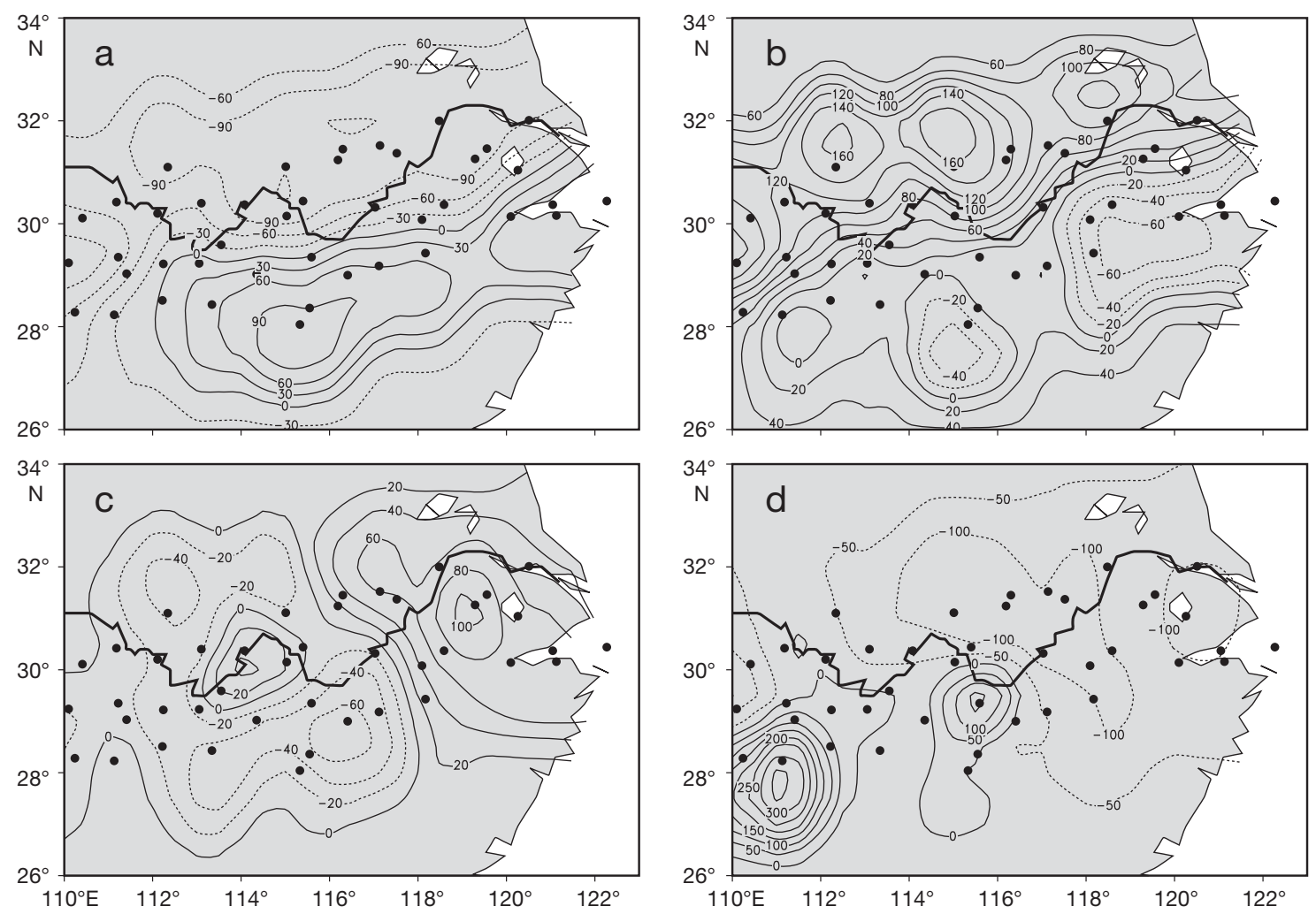

Fig. 3. Composite anomalies of Meiyu rainfall (mm) for the years with (a) the 'south flood and north drought' (SF/ND), (b) 'south drought and north flood' (SD/NF), (c) the 'east wet and west dry' (EW/WD) and (d) 'east dry and west wet' (ED/WW) pattern. Dashed contour lines are used for negative values

not favor the westward expansion and northward move of the WPSH as well as the enhancement and northward advance of the East Asian summer monsoon (EASM). As a result, the southwesterly winds from the Bay of Bengal affect mainly the Jiangnan region (i.e. the southern part of the JHB), leading to a southward shift of the Meiyu rainbelt and resulting in the SF/ND pattern.

In the SD/NF years (Fig. 4b), positive anomalies of $500 \mathrm{hPa}$ height cover most of East Asia, with a positive anomaly center located from the JHB to southwest of Japan. This suggests that the WPSH is northward of its normal position. Consequently, this would favor a northward movement of the EASM, resulting in a northward shift of the Meiyu rainfall in the JHB and thus the SD/NF pattern.

The SF/ND minus SD/NF difference map of $500 \mathrm{hPa}$ height anomalies (Fig. 4c) shows features similar to Fig. 3a, with the coastal trough deepened more. This prevents the WPSH from westward expansion and northward jump, which in turn hinders EASM's northward advancement. These anomaly circulation patterns are thus largely responsible for the out-of-phase Meiyu patterns represented by EOF 2 .
The results from the composite analysis were verified by regression analysis (Fig. 5).

On the $850 \mathrm{hPa}$ level, where moisture transport and convergence are directly coupled to monsoon rainfall, wind anomalies in the SF/ND years (Fig. 6a) show a cyclonic anomaly circulation over South China in the Meiyu period, and northeasterly anomaly winds over the Jiangnan region. This suggests that the EASM winds should be weaker than normal in Southeast China and that the associated Meiyu rainband can not extend as far north as usual. The cyclonic anomaly circulation over South China enhances the cyclonic vorticity over the Jiangnan region, resulting in above normal rainfall in that part of the country. This cyclonic anomaly circulation is accompanied by a strong anti-cyclonic anomaly center over the subtropical western Pacific and a weak anti-cyclonic anomaly center around the Liaodong Peninsula in Northeast China. These systems form the anomaly circulation patterns on the $850 \mathrm{hPa}$ level and are responsible for the SF/ND pattern in the Meiyu region.

An almost entirely reversed situation happens in the SD/NF years (Fig. 6b), when the South China seaboard (including Taiwan) is occupied by an anti- 

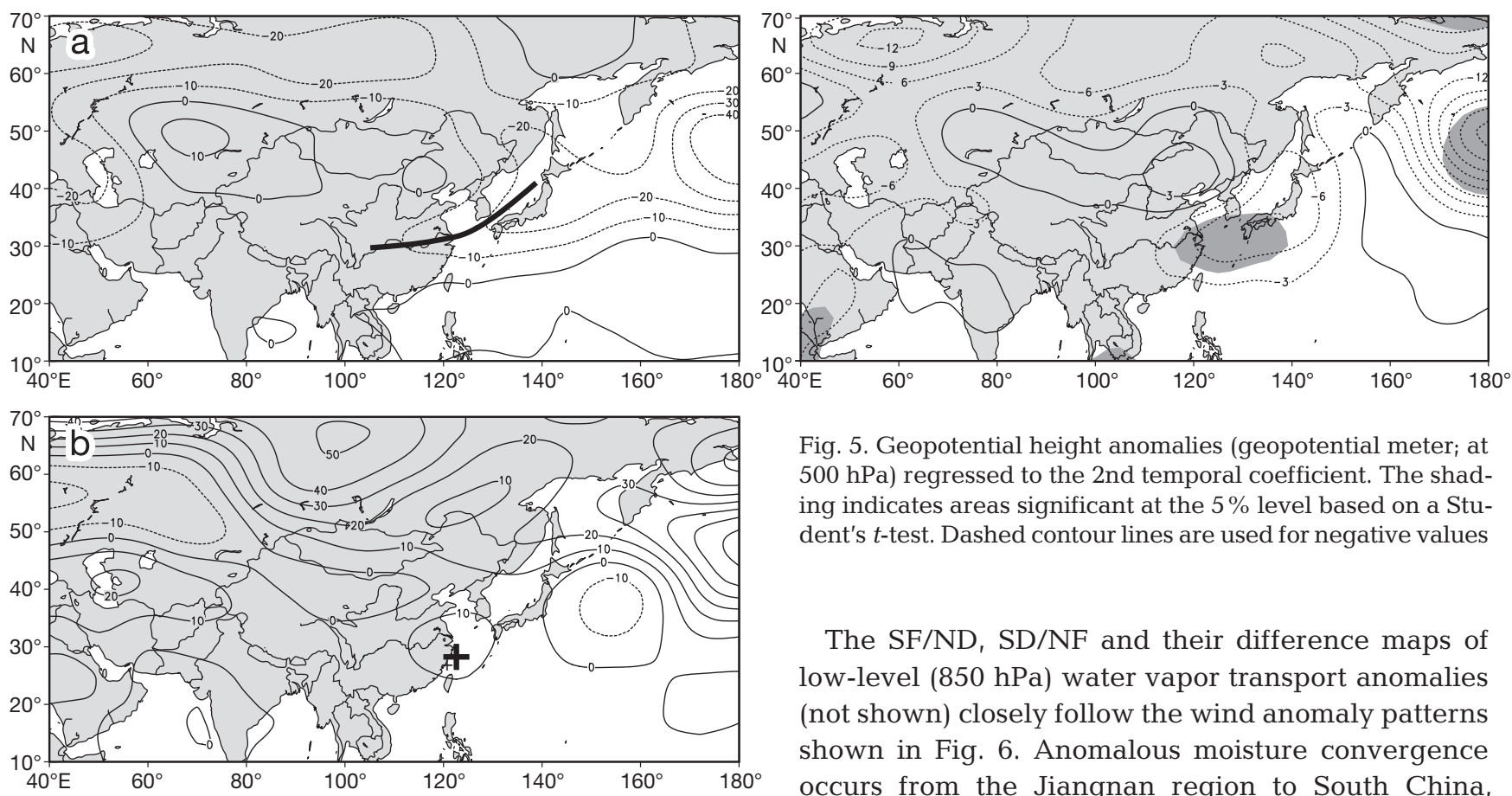

Fig. 5. Geopotential height anomalies (geopotential meter; at $500 \mathrm{hPa}$ ) regressed to the 2 nd temporal coefficient. The shading indicates areas significant at the $5 \%$ level based on a Student's $t$-test. Dashed contour lines are used for negative values

The SF/ND, SD/NF and their difference maps of low-level $(850 \mathrm{hPa})$ water vapor transport anomalies (not shown) closely follow the wind anomaly patterns shown in Fig. 6. Anomalous moisture convergence occurs from the Jiangnan region to South China, while moisture divergence is seen north of the

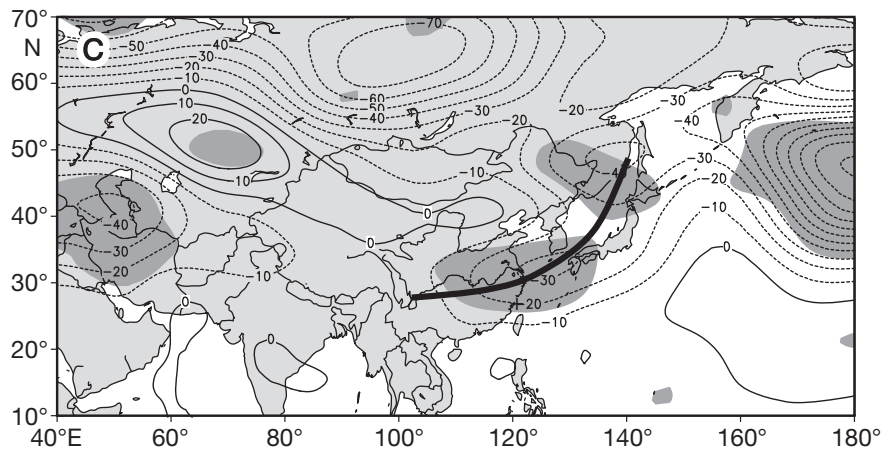
Yangtze River valley during the SF/ND years and vice versa during $\mathrm{SD} / \mathrm{NF}$ years.

During the Meiyu period, the South Asian High on the $200 \mathrm{hPa}$ level tends to be very strong, centered over the plateau north of the Bay of Bengal, with a westerly jet on its north side around $37.5^{\circ}-40^{\circ} \mathrm{N}$ (not shown). Between the SF/ND and SD/NF years, the upper-level circulation exhibits noticeable discrepancies. The SF/ND minus SD/NF difference map of the $200 \mathrm{hPa}$ zonal wind (Fig. 7) shows westerly (easterly) anomaly winds to the south (north) of the long-term mean position of the upper-tropospheric jet-stream around $35^{\circ}-40^{\circ} \mathrm{N}$. With the positive anomalies to the south of the normal jet position, Fig.7 suggests a southward shift of the upper-tropospheric jet during the SF/ND years, which in turn pushes the WPSH and the Meiyu rain belt to a southward position. During the SD/NF years, it is just the opposite. Thus, the Meiyu south-north dipole pattern represented by EOF 2 is also tightly coupled with the south- and northward movements of the upper tropospheric westerly jet. This result is consistent with previous studies (Li et al. 2004, Kuang \& Zhang 2006, Du et al. 2008) that have noticed the importance of the position of the upper tropospheric jet to Meiyu rainfall.

To examine the vertical anomaly circulation, Fig. 8a shows a height-latitude cross section of meridional anomaly circulation averaged along $110.0^{\circ}-$ $122.5^{\circ} \mathrm{E}$ for the SF/ND years. An ascending (descending) anomaly motion exists south (north) of $\sim 30.5^{\circ} \mathrm{N}$, 

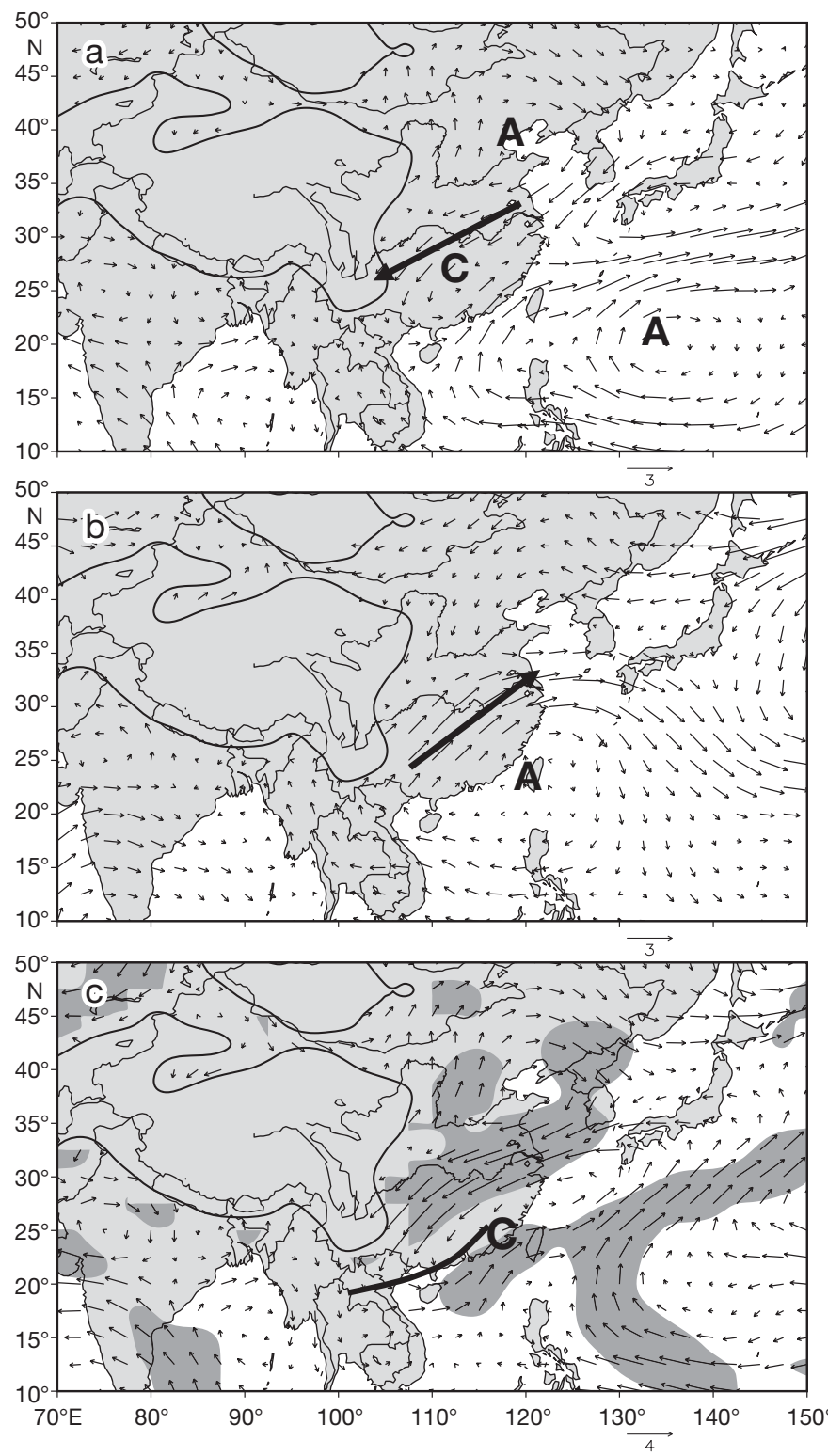

Fig. 6. Composite anomalies of $850 \mathrm{hPa}$ wind vectors $\left(\mathrm{m} \mathrm{s}^{-1}\right)$ for years with (a) the SF/ND and (b) SD/NF pattern, and (c) their difference (SF/ND minus SD/NF); see Table 1 for definitions. In (a), the positions of a cyclonic anomaly circulation (C), northeasterly anomaly winds (long arrow) and a strong anticyclonic anomaly center (A) are shown. In (b), the positions of an anti-cyclonic anomaly center (A) and southwesterly anomaly winds (long arrow) are indicated. In (C), the shading indicates areas significant at the $5 \%$ level based on a Student's $t$ test and the positions of a strong wind shear (thick line) and the cyclonic anomaly circulation (C) are shown

which contributes to the excess (lack) of rainfall in the south (north) of the JHB (cf. Fig. 2c). In the SD/NF years (Fig. 8b), the ascending and descending anomaly motions are approximately reversed around $30^{\circ} \mathrm{N}$, leading to the SD/NF rainfall pattern. Fig. 8b also shows that anomalous southerly winds exist

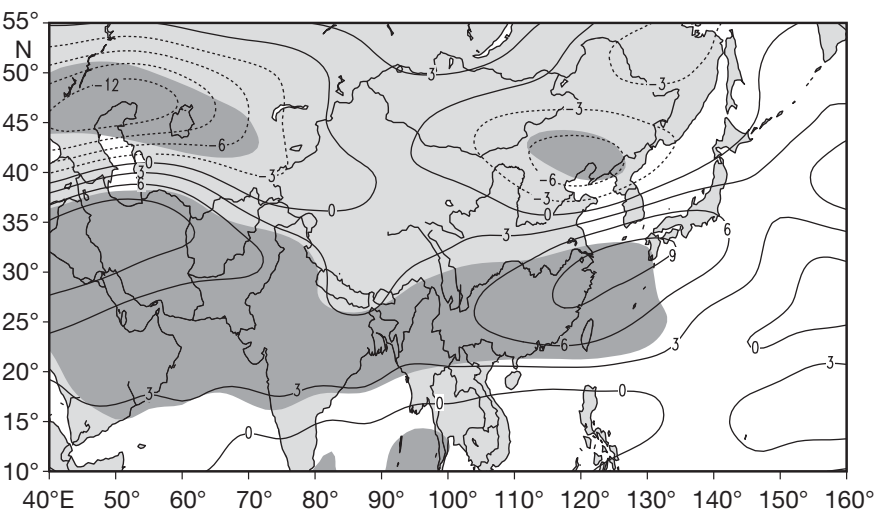

Fig. 7. The SF/ND minus SD/NF composite difference of $200 \mathrm{hPa}$ zonal winds $\left(\mathrm{m} \mathrm{s}^{-1}\right)$. Shading indicates areas significant at the $5 \%$ level based on a Student's $t$-test. See Table 1 for definitions. Dashed contour lines are used for negative values

throughout the middle to lower troposphere at the subtropical latitudes. This implies a strong EASM that favors a northward shift of the Meiyu rainbelt.

\subsection{Anomaly circulations associated with the EW/WD and ED/WW Meiyu patterns}

A composite analysis was conducted using the 4 EW/WD years and the ED/WW year (Table 1). Fig. 9a shows that in the EW/WD years the ridge line of the WPSH is close to its normal position, but the WPSH (defined by the 5880 geopotential meter contour line) is shifted eastward, and becomes flatter and weaker, with the Asian continent covered by a ridge-trough pattern. In the ED/WW year (Fig. 9b), the WPSH ridge line is displaced northwestward, with the Asian continent under the control of 2 ridges and 1 trough. In Fig. 9a, the continental trough is eastward of its normal position, making the precipitation in front of the trough eastward of its normal position as well. This likely contributes to the EW/WD pattern in the JHB region. In contrast, in the ED/WW year, the continental trough is westward of its normal position, which displaces the frontal rainfall westward of its normal position (i.e. over the western part of the JHB). Regression analysis revealed similar results (Fig. 10).

The EW/WD minus ED/WW difference map of $850 \mathrm{hPa}$ wind anomalies (Fig. 11) shows a cyclonic anomaly circulation over the western North Pacific, just south of Japan. This cyclonic center induces northerly anomaly winds over the eastern part of the JHB, while the western JHB experiences southwesterly anomaly winds. This suggests that in the 

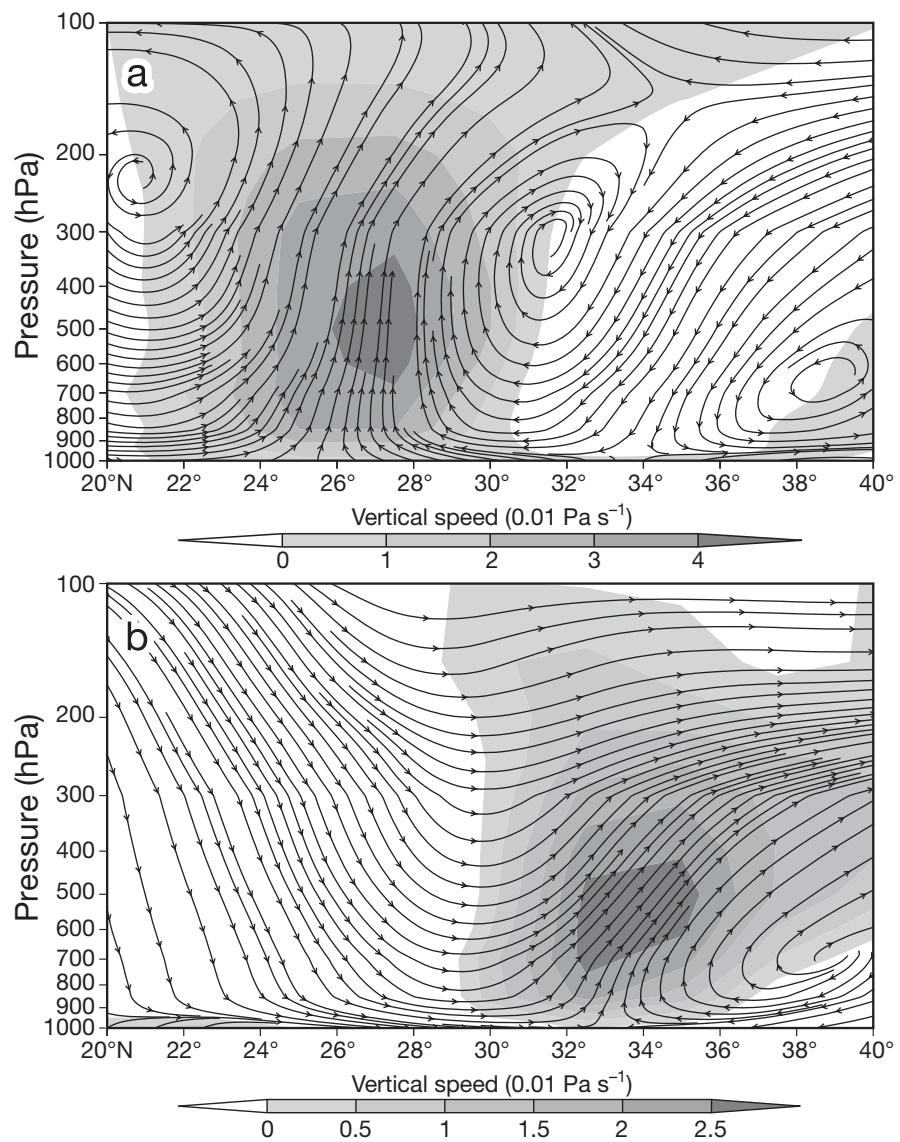

Fig. 8. Composite anomalies of vertical-meridional circulation averaged over $110^{\circ}-122.5^{\circ} \mathrm{E}$ for (a) the SF/ND years and (b) the SD/NF years (see Table 1 for definitions). The vertical speed is in units of $0.01 \mathrm{~Pa} \mathrm{~s}^{-1}$. The shaded areas denote rising motion while descending occurs over the unshaded areas

EW/WD years the monsoon winds over the eastern (western) JHB are weaker (stronger) than in normal years. The anomaly wind patterns are the opposite in the ED/WW year. These differences in the monsoon winds between the eastern and western part of the JHB affect the moisture transport and convergence in the lower troposphere (Fig. 12), thus contributing to the east-west dipole pattern of the Meiyu rainfall.

The EW/WD minus ED/WW difference map of lowlevel water vapor transport (Fig. 12) shows that there is a large northerly anomaly vapor flux being advected from the Yellow and East China Seas and converged into the eastern part of the JHB. Over the western part of the JHB, southwesterly anomaly vapor fluxes dominate, with anomaly moisture divergence (thus drier conditions) during the EW/WD years. The southwesterly vapor flux is advected further northward and converges over central North China, leaving the western part of the JHB relatively dry.
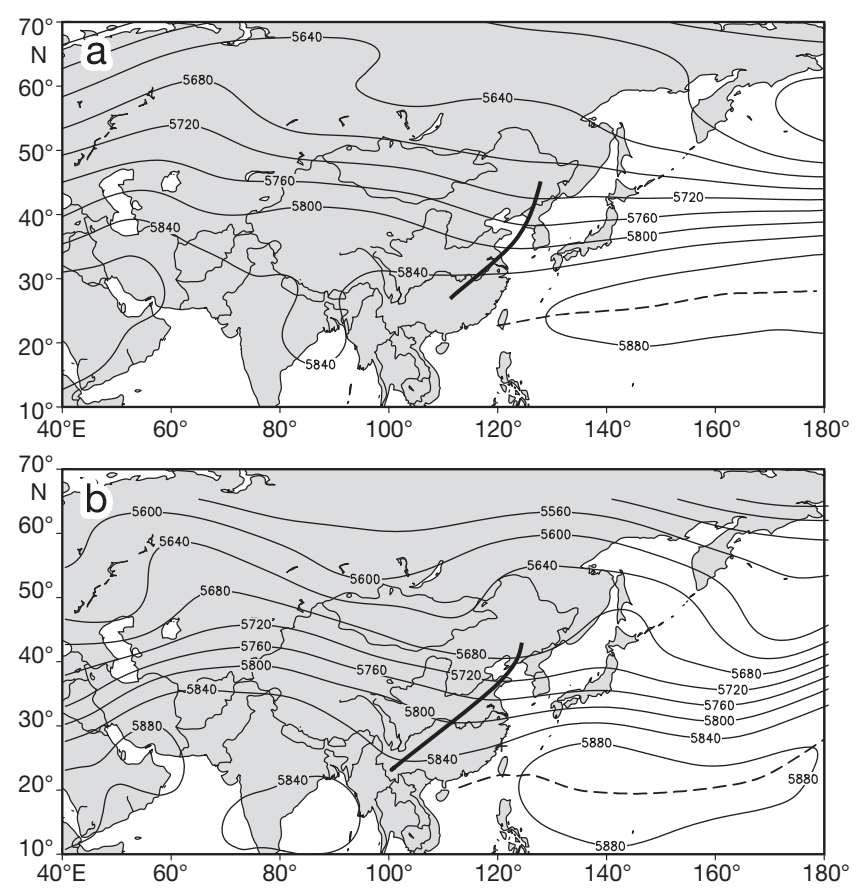

Fig. 9. Composite maps of the $500 \mathrm{hPa}$ geopotential height (geopotential meter) for (a) the 'east wet and west dry' (EW/WD) and (b) 'east dry and west wet' (ED/WW) years. The positions of the continental trough (thick black line) and the ridge line of the Western Pacific subtropical high (dashed line; defined by the 5880 contour line) are shown

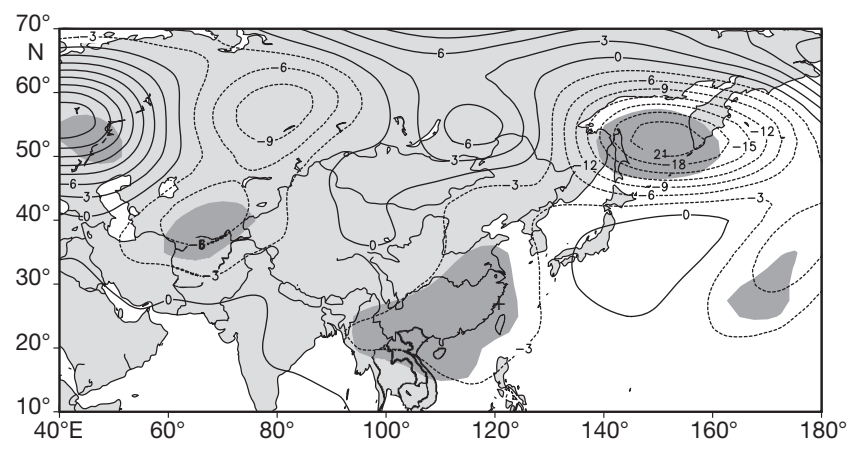

Fig. 10. Geopotential height anomalies (geopotential meter) at $500 \mathrm{hPa}$ regressed to the $3 \mathrm{rd}$ temporal coefficient. The shading indicates areas significant at the $5 \%$ level based on a Student's $t$-test. Dashed contour lines are used for negative values

\section{SUMMARY}

Based on spatial patterns of correlation between Meiyu rainfall at Huangshan station (at the heart of the Meiyu region) and other stations, we selected 42 stations in the JHB region. An EOF analysis of the Meiyu rainfall from 1978 to 2007 at these 42 stations revealed 3 different modes of variability that are statistically significant. The first mode dominates the 


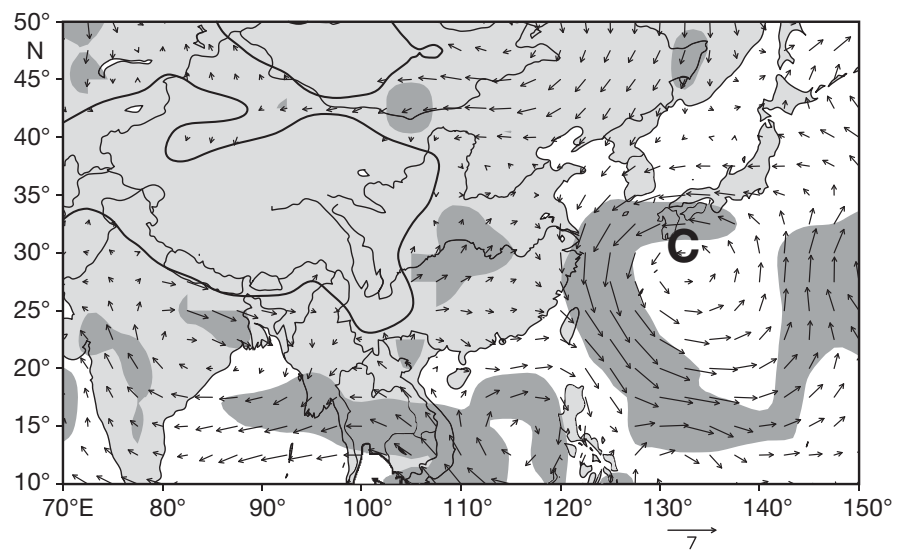

Fig. 11. The EW/WD minus ED/WW composite difference of $850 \mathrm{hPa}$ wind vector $\left(\mathrm{m} \mathrm{s}^{-1}\right)$; see Table 1 for definitions. The shading denotes the areas statistically significant at the $5 \%$ level based on a Student's $t$-test and (C) denotes the position of a cyclonic anomaly circulation

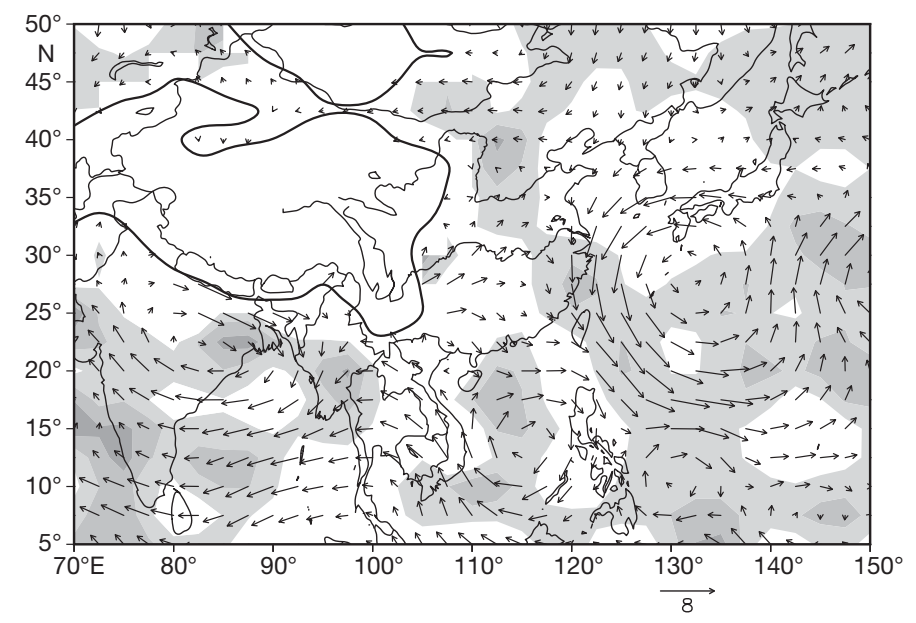

Fig. 12. The EW/WD minus ED/WW composite difference of $850 \mathrm{hPa}$ water vapor fluxes $\left(\mathrm{g} \mathrm{s}^{-1} \mathrm{hPa}^{-1} \mathrm{~cm}^{-1}\right)$. The shading denotes convergence while the unshaded areas represent divergence of moisture

Meiyu variability, accounting for $68 \%$ of the total variance. It primarily consists of multi-year (4 to $5 \mathrm{yr}$ ) variations with the same phase across the whole JHB region. This mode has been examined extensively in many previous studies (e.g. Mao et al. 2008, Hu et al. $2008)$. The second (11.2\% variance) and third (4.3\% variance) EOF modes show substantial regional variations of Meiyu rainfall within the JHB. These 2 patterns are often associated with years with severe floods and severe droughts in the region, consistent with previous findings (e.g. Zhu et al. 2007, Min \& Qian 2009, Qian et al. 2009). Composite analyses using the NCEP/NCAR reanalysis data were performed to characterize the anomaly circulation patterns associated with the second and third EOF modes.
The second EOF mode (Fig. 2c,d) depicts a southnorth dipole (out-of-phase) pattern over the JHB that varies mainly on decadal time scales with relatively small interannual variations. The 2 phases of this mode over the JHB are referred to as SF/ND and $\mathrm{SD} / \mathrm{NF}$ patterns. The SF/ND Meiyu pattern is associated with a southward displacement of the WPSH in the $500 \mathrm{hPa}$ level, a cyclonic anomaly circulation at the $850 \mathrm{hPa}$ level over Southeast China, a southward shift of the upper-tropospheric jet over East Asia, and an ascending (descending) anomaly motion south (north) of $\sim 30^{\circ} \mathrm{N}$ over the JHB sector. Together, these anomaly conditions prevent the EASM from moving as far north as in normal years, resulting in wetter conditions in the southern part (south of $\sim 30^{\circ} \mathrm{N}$ ) and less rainfall in the northern part of the JHB during the $\mathrm{SF} / \mathrm{ND}$ years. Conversely, the SD/NF pattern is associated with a northward shift of the WPSH, a descending (ascending) anomaly motion south (north) of $\sim 30^{\circ} \mathrm{N}$ over East China, and an anti-cyclonic anomaly circulation around the coastal regions in Southeast China, which induces stronger southwesterly winds over the JHB, thereby allowing the EASM to move northward of its normal position. This causes Meiyu rainfall to be above normal in the northern part and below normal in the southern part of the JHB.

The third EOF mode (Fig. 2e-f) shows a roughly east-west dipole (out-of-phase) pattern that varies mainly on interannual time scales. We refer to the 2 phases of this mode as the EW/WD and ED/WW patterns, with the eastern (western) part of the JHB roughly corresponding to the lower (middle) part of the Yangtze River valley. During the EW/WD years, the WPSH is displaced eastward, and a cyclonic anomaly circulation centered south of Japan brings more moisture from the Yellow and East China Seas into the eastern part of the JHB, while southwesterly vapor fluxes pass over the western part of the JHB and converge over North China, leaving the western part of the JHB relatively dry. During the ED/WW year, the WPSH is shifted northwestward, and the anomaly moisture transports are reversed over the JHB region.

Some studies have indicated the impacts of El Nino Southern Oscillation (ENSO), the Indian Ocean dipole and ENSO Modoki on boreal summer monsoon rainfall (Guan \& Yamagata 2003, Ashok et al. 2009). Wang et al. (2000) suggested that ENSO affects East Asian climate mainly by East Asian-Pacific or Japanese-Pacific teleconnection. We will further discuss the previous ocean-atmospheric characteristics corresponding to the diverse spatial patterns in Meiyu rainfall in an upcoming study. 
Acknowledgements. This work was jointly supported by the Chinese National Key Technology R\&D Program (Grant Nos. 2007BAC29B02 and 2009BAC51B01), the National Natural Science Foundation of China (Grant No. 40975057), PhD Programs Foundation of the Ministry of Education of China (Grant No. 20093228120001), '333' Project of Jiangsu Province and the Priority Academic Program Development of Jiangsu Higher Education Institutions. NCEP/NCAR reanalyses are from the website at www.cdc.noaa.gov. The National Center for Atmospheric Research is sponsored by the US National Science Foundation. All figures in this paper were prepared using GrADS. We thank 3 anonymous reviewers for helpful comments and suggestions.

\section{LITERATURE CITED}

Ashok K, Behera SK, Rao SA, Weng H, Yamagata T (2007) El Niño Modoki and its possible teleconnection. J Geophys Res 112:C11007, doi:10.1029/2006JC003798

> Ashok K, Iizuka S, Rao SA, Saji NH, Lee WJ (2009) Processes and boreal summer impacts of the 2004 El Niño Modoki: an AGCM study. Geophys Res Lett 36:L04703, doi:10. 1029/2008GL036313

Chen GTJ (2004) Research on the phenomena of Meiyu during the past quarter century: an overview. In: Chang PC (ed) East Asian Monsoon. World Scientific Publishing, Singapore, p 561-562

Ding YH (1992) Summer monsoon rainfall in China. J Meteorol Soc Jpn 70:373-396

> Ding YH, Chan JCL (2005) The East Asian summer monsoon: an overview. Meteorol Atmos Phys 89:117-142

Ding YH, Liu JJ, Sun Y, Liu YJ, He JH, Song YF (2007) A study of the synoptic-climatology of the Meiyu system in East Asia. Chin J Atmos Sci 31:1082-1101 (in Chinese)

Du Y, Zhang YC, Xie ZQ (2008) Impacts of longitude location changes of East Asian westerly jet core on the precipitation distribution during Meiyu period in middlelower reaches of Yangtze River valley. Acta Meteorol Sin 66:566-576 (in Chinese)

Guan Z Y, Yamagata T (2003) The unusual summer of 1994 in East Asia: IOD teleconnections. Geophys Res Lett 30: 1544, doi:10.1029/2002GL016831

Hu YM, Ding YH, Liao F (2008) A study of updated definition and climatological characters of Meiyu season in the Yangtze-Huaihe region. Chin J Atmos Sci 32:101-112

Huang QL, Wang LJ, He JH, Guan ZY (in press) Determination of the onset and ending of regional Meiyu over Yangtze-Huaihe river valley and its characteristics. J Trop Meteorol

Kalnay E, Kanamitsu M, Kistler R, Collins W and others (1996) The NCEP/NCAR 40-year reanalysis project. Bull Am Meteorol Soc 77:437-470

Kripalani RH, Kulkarni A (2001) Monsoon rainfall variations and teleconnections over South and East Asia. Int J Climatol 21:603-616

Kuang XY, Zhang YC (2006) Impact of the position abnormalities of East Asian subtropical westerly jet on summer precipitation in middle-lower reaches of Yangtze River. Plateau Meteorol 25:382-389 (in Chinese)

> Lau KM, Yang S (1997) Climatology and interannual variability of the Southeast Asian summer monsoon. Adv Atmos Sci 14:141-162
Lee E, Chase TN, Rajagopalan B (2008) Highly improved predictive skill in the forecasting of East Asian summer monsoon. Water Resour Res 44:W10422, doi:10.1029/ 2007WR006514

> Lee E, Chase TN, Rajagopalan B, Barry RG, Biggs TW, Lawrence PJ (2009) Effects of irrigation and vegetation activity on early Indian summer monsoon variability. Int J Climatol 29:573-581

Li CY, Wang JT, Lin SZ (2004) The relationship between East Asian summer monsoon activity and northward jump of the upper westerly jet location. Chin J Atmos Sci 28:641-658 (in Chinese)

> Liu YY, Ding YH (2008) Teleconnection between the Indian summer monsoon onset and the Meiyu over the Yangtze River Valley. Sci China D Earth Sci 51:1021-1035

Lu JN, Xu JF (1990) Climatic analysis of the 1954-1983 Meiyu rainfall over the middle and lower basin of the Changjiang River. J Nanjing Inst Meteorol 13:228-237 (in Chinese)

Lu CH, Guan ZY, Cai JX (2010) Interhemispheric atmospheric mass oscillation and its relation to interannual variations of the Asian monsoon in boreal summer. Sci China Earth Sci 53:1343-1350

Mao WS, Wang QQ, Li GP (2008) Analyses on the general circulation characteristics of Meiyu over the ChangjiangHuaihe valley. Plateau Meteorol 27:1267-1275 (in Chinese)

Mao WS, Wang QQ, Li GP, Zhu KY (2009) Characters of the water vapor transfer in the Changjiang-Huaihe River valley. J Trop Meteorol 25:234-240 (in Chinese)

Min S, Qian YF (2009) Comparative investigation on Meiyu parameters in different subregions of the ChangjiangHuaihe valley. J Appl Meteorol Sci 19:19-27 (in Chinese)

Ninomiya K (2000) Large- and meso-alpha-scale characteristics of Meiyu/Baiu front associated with intense rainfalls in 1-10 July 1991. J Meteorol Soc Jpn 78:141-157

Ninomiya K, Murakami T (1987) The early summer rainy season (Baiu) over Japan. In: Chang CP, Krishnamurti TN (eds) Monsoon meteorology. Oxford University Press, p 93-121

Niu RY, Su AF, Ma J, Lv XD (2011) The difference of the atmospheric circulation features and dynamical diagnosis about the typical Meiyu patterns of southern flood (drought) and northern drought (flood). Chin J Atmos Sci 35:95-104 (in Chinese)

North GR, Bell TL, Cahalan RF (1982) Sampling errors in the estimation of the empirical orthogonal functions. Mon Weather Rev 110:699-706

Qian YF, Wang QQ, Huang DQ (2007) Studies of floods and droughts in the Yangtze-Huaihe River basin. Chin J Atmos Sci 31:1279-1289 (in Chinese)

Qian WH, Zhu J, Wang YG, Fu JL (2009) Regional relationship between the Jiang-Huai Meiyu and the equatorial surface-subsurface temperature anomalies. Chin Sci Bull 54:113-119

Si D, Ding YH, Liu YJ (2009) Decadal northward shift of the Meiyu belt and the possible cause. Chin Sci Bull 54: 4742-4748

Tao SY, Chen LX (1987) A review of recent research on the East Asian summer monsoon in China. In: Chang $\mathrm{CP}$, Krishnamurti TN (eds) Monsoon meteorology. Oxford University Press, New York, NY, p 60-92

Ting MF, Wang H (1997) Summer time U.S. precipitation variability and its relation to Pacific sea surface tempera- 
ture. J Clim 10:1853-1873

Wang ZR, Qian YF (2004) The multiscale characteristics of Meiyu in the Changjiang-Huaihe River valley and its association with the El Nino and the general circulation. J Nanjing Inst Meteorol 27:317-325 (in Chinese)

Wang B, Wu RG, Fu XH (2000) Pacific-East Asian teleconnection: How does ENSO affect East Asian climate? J Clim 13:1517-1536

Xu HM, He JH, Dong M (2001) Interannual variability of the Meiyu onset and its association with the North Atlantic oscillation and SSTA over the North Atlantic. Acta Meteorol Sin 59:694-706 (in Chinese)

Yoshiaki S, Kozo N (2005) Multi-scale interaction processes

Submitted: February 28, 2011; Accepted: July 22, 2011 associated with development of a sub-synoptic-scale depression on the Meiyu-Baiu frontal zone. J Meteorol Soc Jpn 83:219-236

Zhang RH (2001) Relations of water vapor transport from Indian monsoon with that over East Asia and the summer rainfall in China. Adv Atmos Sci 18:1005-1017

Zheng YG, Chen J, Ge GQ, Zhu PJ (2008) Typical structure, variety, and multi-scale characteristics of Meiyu front. Acta Meteorol Sin 22:187-201

Zhu XY, He JH, Wu ZW (2007) Meridional seesaw-like distribution of the Meiyu rainfall over the ChangjiangHuaihe River valley and characteristics in the anomalous climate years. Chin Sci Bull 52:2420-2428

Proofs received from author(s): November 6, 2011 